\title{
OSSEOUS AND DENTAL PROBLEMS IN PATIENTS WITH RENAL FAILURE - A CASE REPORT
}

\author{
Balcheva M. ${ }^{1}$, Abadjiev M. ${ }^{2}$, Dencheva M. ${ }^{3}$, Iovchev D. ${ }^{3}$, Kisselova A. ${ }^{3}$ \\ 1) Department of Conservative Dentistry and Pedodontics, \\ 2) Department of Prosthodontics and Orthodontics, \\ Faculty of Dental Medicine, Medical University - Varna, Bulgaria \\ 3) Department of Imaging and Oral Diagnostics, Faculty of Dental Medicine, \\ Medical University - Sofia, Bulgaria
}

\section{SUMMARY:}

We present a case of a patient with severe renal disease and many complications. The patient is fully questioned and tested due to the searched dental focus - his state is not going better in spite of the treatment and the partial parathyroidectomy. The orthopantomograms with the brown tumors in his jaw bones are also interesting.

Key words: renal failure, focus, brown tumor

\section{OBJECTIVES:}

This is a case of a 32-years old male K. P. He has an end stage renal failure and for a year and 8 months is on hemodialysis. He is a potential recipient of a kidney transplant from a living donor (his mother). He has also renal osteodystrophy, secondary hyperparathyroidism, multiple brown tumors of ribs, maxilla, mandible and other bones.

Renal osteodystrophy is a condition due to the chronic kidney disease and renal failure, with elevated serum phosphorus levels, low or normal serum calcium levels, and stimulation of parathyroid function, resulting in a variable admixture of bone disease.

Secondary hyperparathyroidism refers to the excessive secretion of parathyroid hormone (PTH) by the parathyroid glands in response to hypocalcemia (low blood calcium levels) and associated hypertrophy of the glands. Chronic renal failure is the most common cause of secondary hyperparathyroidism. Failing kidneys do not convert enough vitamin $\mathrm{D}$ to its active form, and they do not adequately excrete phosphorus. When this happens, insoluble calcium phosphate forms in the body and removes calcium from the circulation. Both processes lead to hypocalcemia and hence secondary hyperparathyroidism. Bone and joint pain are common, as are limb deformities. The elevated PTH has also pleiotropic effect on blood, immune system and neurological system. If left untreated, the disease will progress to tertiary hyperparathyroidism, where correction of the underlying cause will not stop excess PTH secretion, i.e. parathyroid gland hypertrophy becomes irreversible.

Brown tumors are tumors of bone that arise in settings of excess osteoclast activity, such as hyperparathyroidism, and consist of fibrous tissue, woven bone and supporting vasculature, but no matrix. They are radiolucent on x-ray. The osteoclasts consume the trabecular bone that osteoblasts lay down and this front of reparative bone deposition followed by additional resorption can expand beyond the usual contour of the bone, involving the periosteum and causing bone pain. The characteristic brown coloration results from hemosiderin deposition into the osteolytic cysts.

Table 1: Local thermometric test $\left({ }^{\circ} \mathrm{C}\right)$.

\begin{tabular}{|c|c|c|c|c|c|c|c|c|c|c|c|c|c|c|c|}
\hline & & 35,6 & & & & & & & & & & 34,6 & 35,1 & & \\
\hline 8 & 7 & 6 & 5 & 4 & 3 & 2 & 1 & 1 & 2 & 3 & 4 & 5 & 6 & 7 & 8 \\
\hline 35.8 & 35.7 & 35.4 & 35.1 & 35.1 & 34.8 & & & & & 35.3 & 35.1 & 35.0 & 35.5 & 35.6 & 35.8 \\
\hline
\end{tabular}

Table 2: Vitality test $(\mu \mathrm{A})$.

\begin{tabular}{|c|c|c|c|c|c|c|c|c|c|c|c|c|c|c|c||}
\hline 8 & 7 & 6 & 5 & 4 & 3 & 2 & 1 & 1 & 2 & 3 & 4 & 5 & 6 & 7 & 8 \\
\hline & 4 & 4 & 200 & 200 & & 15 & 200 & 200 & 30 & & 200 & 200 & 200 & 200 & \\
\hline
\end{tabular}




\section{METHODS:}

The patient came to us for focal diagnostics because of the awaited transplantation. He was took full anamnesis, oral and hygienic status. Then several tests - local thermometric, pathogalvanism and vitality test - were made. ${ }^{4}$ We could not use the Gehlen test because of the darker complexion of the man. A new OPG (orthopantomogram) was prescribed.

Picture 1: $O P G-08.2009$

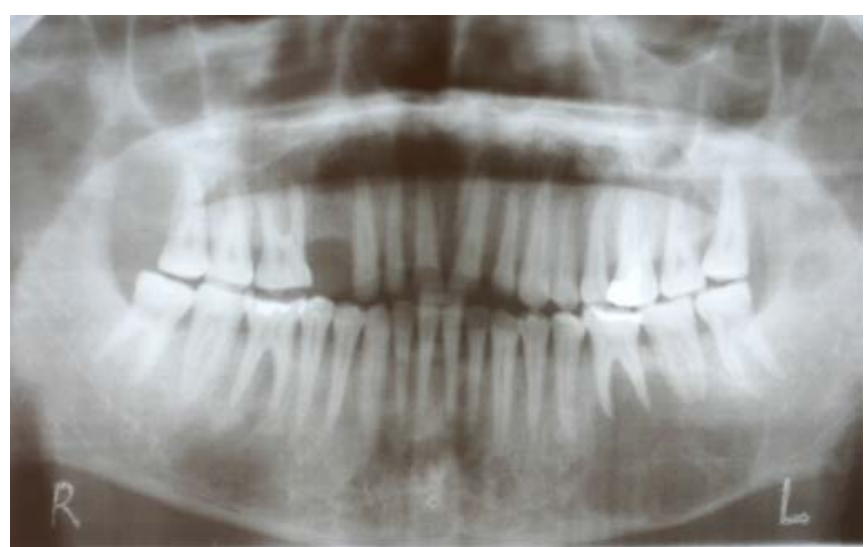

Picture 2: $\mathrm{OPG}-03.2010$

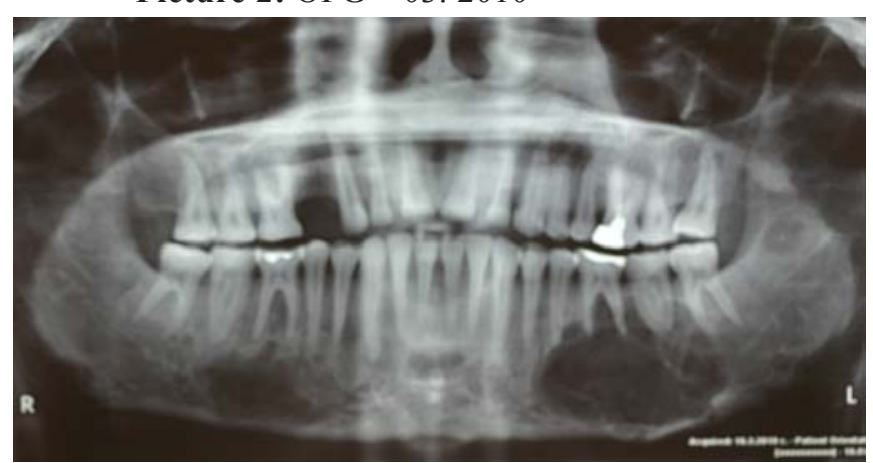

\section{RESULTS:}

The patient's dental status is good - he has 2 extracted teeth, 3 fillings ( 1 amalgam and 2 composite fillings) and 1 caries. The hygienic status is also satisfying - only mild gingivitis. On that account the amalgam filling is replaced due to its high corrosive value $(-230 \mathrm{mV})$ and full mouth scaling is accomplished.

Comparing two orthopantomograms - the new one and one from August 2009 - we notice that the brown tumors in the mandible persist in spite of the treatment and the partial parathyroidectomy. The vitality test shows that teeth 37,36 , $35,34,31,41,44$ and 45 are practically not vital, but the patient has no sensibility in his left facial side. The local thermometric test does not define them as active foci also. In that case, the thermograghic test could probably clear up the picture.

\section{CONCLUSIONS:}

It is very hard to help patients like this. The perfect treatment plan and useful specialists' collaboration are obviously not enough. And may be every effort or manipulation will bring more harm than help. And we can treat only the complications, but not prevent them already.

\section{REFERENCES:}

1. Triantafillidou K, Zouloumis L, Karakinaris G, Kalimeras E, Iordanidis F. Brown tumors of the jaws associated with primary or secondary hyperparathyroidism. A clinical study and review of the literature. Am J Otolaryngol. 2006 Jul-Aug; 27(4): 281-6.
2. Tarello F, Ottone S, De Gioanni PP, Berrone S. Brown tumor of the jaws. Minerva Stomatol. 1996 Oct; 45(10):46570 .

3. Sutbeyaz Y, Yoruk O, Bilen H, Gursan N. Primary hyperparathyroidism presenting as a palatal and mandibular brown tumor. J Craniofac Surg. 2009 Nov; 20(6):2101-4.

4. Petrunov, B., Dimitrov, V., Kisselova-Yaneva, A. Clinical immunology. Clinical allergology. Dental clinical allergology. ARSO Med. Publ., 2009, $1^{\text {st }}$ ed.

\author{
Address for correspondence: \\ D-r Miglena Balcheva \\ Faculty of Dental Medicine, Medical University - Varna, \\ 150, Tzar Osvoboditel Boul., office 623; 9002 Varna, Bulgaria \\ Tel.: +359888571862 \\ E-mail: dr_balcheva@abv.bg
}

